\title{
REMOÇÃO DE AMÔNIA EM EFLUENTE AQUÍCOLA UTILIZANDO QUITOSANA OBTIDA POR DIFERENTES MÉTODOS DE SECAGEM
}

\author{
. K. ARANTES ${ }^{1}$, C. L. KUGELMEIER ${ }^{1}$, L. M. S. COLPINI ${ }^{1}$, I. V. ZADINELLO ${ }^{1}$, L. D. dos \\ SANTOS $^{1}$, H. J. ALVES ${ }^{1}$ \\ ${ }^{1}$ Universidade Federal do Paraná, Setor Palotina \\ E-mail para contato: helquimica@yahoo.com.br
}

RESUMO - O biopolímero quitosana pode ser obtido através da reação de desacetilação da quitina, polissacarídeo encontrado no exoesqueleto de crustáceos. Neste trabalho, a quitosana foi obtida a partir de carapaças de camarão de água doce cultivados na região oeste do Paraná, sendo submetida aos processos de secagem em estufa elétrica (EE) e utilizando $\mathrm{CO}_{2}$ supercrítico (CS). As amostras foram caracterizadas por RMN ${ }^{1} \mathrm{H}$, FTIR, fisissorção de $\mathrm{N}_{2}$ (B.E.T.) e $\mathrm{MEV}$ e aplicadas na remoção de amônia em efluentes sintéticos uma vez que este composto influencia fortemente na dinâmica do oxigênio dissolvido no meio aquático, afetando a fisiologia dos organismos. Os resultados indicaram que a secagem em CS aumentou drasticamente a área superficial e o volume de poros bem como a eficiência de remoção de amônia em efluentes sintéticos, sendo possível remover 68,8\% e 98,2\% de íons amônio utilizando as amostras secas por EE e $\mathrm{CS}$, respectivamente, após 3 horas de agitação em pH 7,5 a temperatura ambiente, com apenas $0,05 \%(\mathrm{~m} / \mathrm{m})$ de quitosana.

\section{INTRODUÇÃO}

A indústria pesqueira tem entre seus rejeitos matérias primas de grande importância, tais como carapaças de caranguejos e de camarões, das quais pode-se extrair quitina, polissacarídeo que pode ser processado quimicamente resultando em quitosana, um biopolímero com diversas possibilidades de aplicação devido, dentre outros fatores, às propriedades que lhe conferem os grupos amino (- $\left.\mathrm{NH}_{2}\right)$, obtidos pela conversão dos grupamentos acetamido $\left(-\mathrm{NHCOCH}_{3}\right)$ (Figura 1). Suas aplicações industriais e tecnológicas vêm sendo exploradas há décadas podendo-se citar como exemplo a produção de cosméticos, drogas e medicamentos, aditivos alimentícios, membranas semipermeáveis, desenvolvimento de biomateriais e na indústria têxtil, como alternativa no tratamento de efluentes com a presença de corantes. 


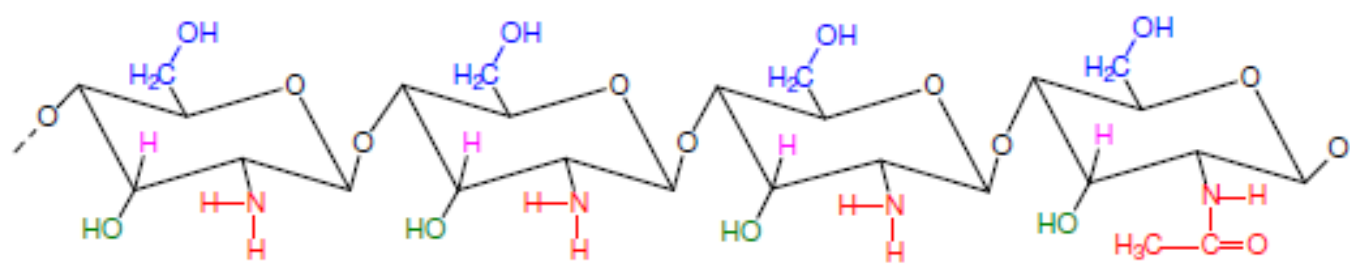

Figura1: Estrutura do biopolímero quitosana onde predominam grupos amino $\left(\mathrm{NH}_{2}\right)$ resultantes da desacetilação de grupos acetamida $\left(-\mathrm{NHCOCH}_{3}\right)$ da quitina.

A potencialidade deste tipo de resíduo, que corresponde a $40 \%$ da produção, deve-se à sua composição: altos teores de quitina (15-20\%), proteínas (25-40\%), sais inorgânicos (cinzas 40-55\%) e pigmentos carotenóides (cerca de 15\%) (Tolaimate et al., 2003). No Brasil há grande disponibilidade deste tipo de resíduo no litoral, e em menor ocorrência, no interior: é o caso da região oeste do Paraná devido à crescente produção de camarão de água doce em consórcio com o cultivo de tilápia em tanques escavados; este fato, aliado aos aspectos promissores de aplicação de quitosana em diversas áreas, motivou-nos a produzir em nosso laboratório este biopolímero, com elevado grau de desacetilação (GD). Quanto mais elevado for o GD da quitosana maior será a influência, do ponto de vista químico, sobre algumas de suas propriedades, como por exemplo, hidrofobia, capacidade de sofrer reticulação mediante agentes de entrecruzamento, solubilidade e viscosidade em soluções. As quitosanas comerciais possuem, geralmente, GD variando de 70 a 95\%, com massa molecular na faixa de $10^{4}$ a $10^{6} \mathrm{kDa}$ e estrutura semicristalina.

No processamento de quitina para obtenção de quitosana, a etapa de secagem deve ser manipulada de modo a manter as características originais do produto ou então visando modificações de interesse, além de assegurar-lhe umidade adequada para fins de armazenamento e comercialização. Dentre os métodos de secagem que podem ser aplicados à quitosana, pode-se destacar alguns: secagem em estufa; por liofilização por Spray drying e pelo método inserido neste trabalho, utilizando $\mathrm{CO}_{2}$ supercrítico (SAS- Supercritical Antisolvent Precipitation) e estudos avaliando a influência da técnica de secagem sobre as propriedades da quitosana têm sido relatados (Garcia-Bermenjo et al. (2012).

Devido às propriedades de quitosana que favorecem a adsorção, testou-se neste trabalho o uso deste material para a remoção de íons amônio $\left(\mathrm{NH}_{4}{ }^{+}\right)$em efluentes aquícolas. Sabe-se que dentre os compostos nitrogenados dissolvidos na água o íon $\mathrm{NH}_{4}{ }^{+} \mathrm{e}$ a amônia $\left(\mathrm{NH}_{3}\right)$ constituem a amônia total ou nitrogênio amoniacal total, também chamado simplesmente de amônia (Arana, 2010) e no meio aquático, especialmente quando o $\mathrm{pH}$ é ácido ou neutro, a amônia formada é instável, sendo convertida por hidratação a íon amônio $\left(\mathrm{NH}_{4}{ }^{+}\right)$. Em meio alcalino, a possibilidade de ocorrência desse processo é muito reduzida, podendo causar aumento da concentração da forma não ionizada $\left(\mathrm{NH}_{3}\right)$, que é a forma mais tóxica para os organismos aquáticos. A amônia é ainda o principal produto de excreção dos peixes além de ser gerada da decomposição da matéria orgânica (restos de ração), excesso de adubação orgânica, morte do fitoplâncton, dentre outras fontes (Lazzari \& Baldisserotto, 2008). 


\section{9 a 22 de outubro de 2014 \\ Florianópolis/SC}

Na criação de peixes carnívoros, o aparecimento de altos níveis de amônia na água de cultivo pode ser agravado pelos elevados níveis de proteína das rações. De acordo com Kubitza (2003), valores de amônia não ionizada acima de $0,20 \mathrm{mg} \mathrm{L}^{-1}$ já são suficientes para induzir toxicidade crônica e levar à diminuição do crescimento e da tolerância dos peixes a doenças. Níveis de amônia entre 0,70 e $2,40 \mathrm{mg} \mathrm{L}^{-1}$ podem ser letais para os peixes, quando expostos por curto período. Exposição contínua ou frequente a concentrações de amônia tóxica acima de $0,02 \mathrm{mg} \mathrm{L}^{-1}$ pode causar intensa irritação e inflamação nas brânquias. Dessa forma, deve-se manter baixa a concentração de amônia em cultivo de peixes e evitar grandes alterações da qualidade da água de um sistema artificial de criação.

A necessidade de desenvolvimento de materiais adsorventes, capazes de remover nitrogênio amoniacal de tanques de cultivo de organismos aquáticos motivou-nos a avaliar a performance de quitosana para esta aplicação, após diferentes processos de secagem e sob diferentes simulações de ambiente aquático

\section{MATERIAIS E MÉTODOS}

\subsection{Produção de Quitosana e métodos de secagem}

A quitina foi extraída de exoesqueletos de camarão de água doce Macrobrachium rosenbergii através de desmineralização e desproteinação (Tolaimate et al. 2003) e seguiu para reação de desacetilação nas condições: proporção quitina/base $2,5 \%(\mathrm{~m} / \mathrm{V})$ sendo a base solução de $\mathrm{NaOH} 50 \%$ $(\mathrm{m} / \mathrm{V})$, sob a refluxo por 10 horas a $100^{\circ} \mathrm{C}$. O produto da reação foi lavado até $\mathrm{pH}$ neutro e seco a $60^{\circ} \mathrm{C}$ por 24 horas. Três procedimentos de secagem de quitosana foram testados: dois para secagem em estufa, para as amostras identificadas como Q1 e Q2 e secagem por $\mathrm{CO}_{2}$ supercrítico, para a amostra Q3 (Tabela 1). Em cada caso o preparo da amostra consistiu na solubilização quitosana em $\mathrm{HCl} 0,1 \mathrm{M}$, na proporção de $0,4 \%(\mathrm{~m} / \mathrm{V})$, seguido da precipitação por gotejamento em solução de $\mathrm{NaOH}$ 2,0 M, sob agitação. O material precipitado foi filtrado e lavado com soluções de concentração crescente de etanol absoluto $(10,30,50,70,90$ e $100 \%)$

\subsection{Caracterização físico-química de quitina e quitosana}

A eficiência das etapas de desmineralização e desproteinação no isolamento de quitina foi avaliada pelo teor de cinzas após incineração em mufla a $600^{\circ} \mathrm{C}$ e o conteúdo proteico foi medido por método Kjeldahl e ensaio de Biureto, antes e após os processos. O grau médio de acetilação (GA) das quitosanas foi obtido por RMN ${ }^{1} \mathrm{H}$ e caracterização dos grupos funcionais por espectroscopia na região do infravermelho (FTIR) (Santos et al., 2003). Para verificação da morfologia e tamanho das partículas utilizou-se microscopia eletrônica de varredura (MEV) em um equipamento FEI - Quanta 400. A estrutura porosa e volume de poros obteve-se por Método de fisissorção de Nitrogênio B.E.T.).

\subsection{Testes de Utilização de Quitosana para Remoção de Amônia}

Preparou-se soluções correspondentes a efluentes sintéticos a partir $\mathrm{NH}_{4} \mathrm{Cl}$, sendo o $\mathrm{pH}$ fixo em 
7,5. A concentração de íons $\mathrm{NH}_{4}{ }^{+}$das alíquotas coletadas nos ensaios foram analisadas pelo método do fenato.

Submeteu-se as amostras de quitosana submetidas a diferentes processos de secagem (Q1 e Q2 em estufa) e Q3 (por $\mathrm{CO}_{2}$ supercrítico) aos ensaios para avaliação da capacidade de adsorção de íons amônio variando-se os parâmetros experimentais: Efeito da concentração do adsorvente: Ensaios com $5,2 \mathrm{mg} . \mathrm{L}^{-1}$ de íons $\mathrm{NH}_{4}{ }^{+}$para três concentrações de cada uma das amostras de quitosana (Q1, Q2, Q3): 0,$05 ; 0,1$ e $0,2 \%(\mathrm{~m} / \mathrm{m})$. As suspensões foram agitadas por três horas em câmara incubadora com agitação tipo shaker $(100 \mathrm{rpm})$ e a seguir centrifugadas a $2500 \mathrm{rpm}$ por 2 minutos para análise da concentração de íons $\mathrm{NH}_{4}{ }^{+}$. Foram realizadas quatro repetições de cada condição e eficiência de remoção de amônia (\%) foi determinada conforme Equação 1, utilizando os valores médios. Efeito da concentração de íons $\mathrm{NH}_{4}{ }_{4}$ : concentração de Q1, Q2 e Q3 igual a 0,05\% (m/m) e concentração de íons $\mathrm{NH}_{4}{ }^{+}: 0 ; 0,5 ; 1,0 ; 2,5 ; 5,0 ; 10 ; 20 ; 50$ e $100 \mathrm{mg} \mathrm{L}^{-1}$, mantidas as condições anteriores. A eficiência de remoção de amônia (\%) foi determinada conforme Equação 1.

$$
E R(\%)=\frac{\left(C_{0-} C_{f}\right)}{C_{0}} x 100
$$

Onde ER (\%) corresponde ao teor de íons amônio removidos e $\mathrm{C}_{0}$ e $\mathrm{C}_{\mathrm{f}}$ correspondem às concentração inicial e final de íons amônio no efluente sintético.

\section{RESULTADOS E DISCUSSÕES}

\subsection{Caracterização de quitina e quitosana.}

Os principais parâmetros a serem avaliados com relação à obtenção de quitina dizem respeito à eficiência das etapas de desmineralização (DM) e desproteinação (DP) após os tratamentos ácido e alcalino e ao rendimento em quitina. Avaliou-se neste trabalho o \%DM e \%DP e obteve-se eficiência de $99.8 \%$ e $99.9 \%$, respectivamente. O rendimento em massa $\left(\% \mathrm{~m}^{-1} \mathrm{~m}^{-1}\right)$ de quitina foi de $20 \%$, que está compreendido na faixa de valores para teor de quitina em carapaça de camarão relatados na literatura (Tolaimate et al., 2003). A escolha dos métodos de DM e DP (concentração das soluções, tempo e temperatura) levou em conta que se deve buscar manter a estrutura nativa do biopolímero, minimizando degradação ou desacetilação parcial.

Ao produzir quitosana através de reação de desacetilação da quitina parâmetros chave para sua identificação são o Grau de Desacetilação (GD) e a identificação dos grupos funcionais. Com relação a GD, o método de desacetilação escolhido neste trabalho levou em conta resultados relatados na literatura para desacetilação de quitinas isoladas de camarão com GD superior a 70\% (Tolaimate et al., 2003) considerando-se que diferentes fontes de quitina podem requerer diferentes tempos de reação de desacetilação para chegar ao mesmo GD. Após a purificação da quitosana obtida neste processo realizou-se a caracterização por $\mathrm{RMN}^{1} \mathrm{H}$ e obteve-se os dados apresentados na Tabela 1. 
Tabela1 - Condições de secagem e características físico químicas após o processo

\begin{tabular}{cccccccc}
\hline Amostra & \multicolumn{2}{c}{ Secagem } & & & Porosidade & Desacetilação \\
\hline & Tempo (h) & $\begin{array}{c}\text { Temperatura } \\
\left({ }^{\mathbf{0}} \mathbf{C}\right)\end{array}$ & $\begin{array}{c}\text { Pressão } \\
(\mathbf{b a r})\end{array}$ & $\begin{array}{c}\text { Área } \\
\text { Superficial } \\
\left(\mathbf{m}^{\mathbf{2}} \cdot \mathbf{g}^{-1}\right)\end{array}$ & $\begin{array}{c}\text { Volume } \\
\mathbf{d e ~ P o r o s} \\
\left(\mathbf{c m}^{\mathbf{3}} \cdot \mathbf{g}^{-\mathbf{1}}\right)\end{array}$ & $\begin{array}{c}\text { Tamanho } \\
\mathbf{d e ~ P o r o s} \\
(\mathbf{A})\end{array}$ & GD (\%) \\
\hline $\mathbf{Q 1}$ & 24 & 60 & 1,013 & 1,07 & 0,0055 & 98,2 & 95,8 \\
\hline $\mathbf{Q 2}$ & $1^{\mathrm{a}}: 0,17 ; 2^{\mathrm{a}}: 24^{*}$ & 60 & 1,013 & 16,7 & 0,0469 & 56,2 & 97,2 \\
\hline $\mathbf{Q 3}$ & 2 & 32 & 74,0 & 202,1 & 1,489 & 14,7 & 95,5 \\
\hline
\end{tabular}

* secagem em duas etapas

A identificação dos grupos funcionais referentes a quitina e quitosana foi obtida por Análise espectroscópica vibracional (FTIR) onde bandas características de grupos acetamido e amina foram observados (gráficos não exibidos) e conferem com bandas relatadas na literatura (Santos et al., 2003): banda de estiramento axial de $\mathrm{OH}$ entre 3440 a $3480 \mathrm{~cm}^{-1}$, a qual aparece sobreposta à banda de estiramento $\mathrm{N}-\mathrm{H}$; deformação axial de $\mathrm{C}=\mathrm{O}$ de amida $\mathrm{I}$ (entre 1661 a $1671 \mathrm{~cm}^{-1}$ ); deformação angular de $\mathrm{N}-\mathrm{H}$ (entre 1583 a $1594 \mathrm{~cm}^{-1}$ ); deformação angular simétrica de $\mathrm{CH}_{3}$ (entre 1380 a 1383 $\mathrm{cm}^{-1}$ ); deformação axial de $-\mathrm{CN}$ de amida (por volta de $1425 \mathrm{~cm}^{-1}$ ) e deformação axial de $-\mathrm{CN}$ de grupamentos amino (entre 1308 a $1380 \mathrm{~cm}^{-1}$ ), além de bandas de estruturas polissacarídicas na região de $890-1156 \mathrm{~cm}^{-1}$ Os picos correspondentes aos tipos de ligação nas amostras de quitosana que passaram por processos de secagem diferentes demonstraram que não há variações significativas oriundas do processo se secagem.

Com relação às características superficiais das partículas de quitosana, é possível verificar nas micrografias da Figura 2 que a secagem com $\mathrm{CO}_{2}$ supercrítico - SAS diminuiu significativamente o tamanho das partículas e suas características superficiais (Fig. 3c). As partículas da amostra Q3 possuem formas mais homogêneas e superfícies menos rugosas que as partículas de Q1 e Q2. Comparando as partículas das amostras Q1 (Fig. 3a) e Q2 (Fig. 3b), nota-se que a rápida secagem de um filme de baixa espessura em Q2 resultou em partículas de tamanhos regulares, com superfícies mais rugosas e maior área superficial (Tabela 1).

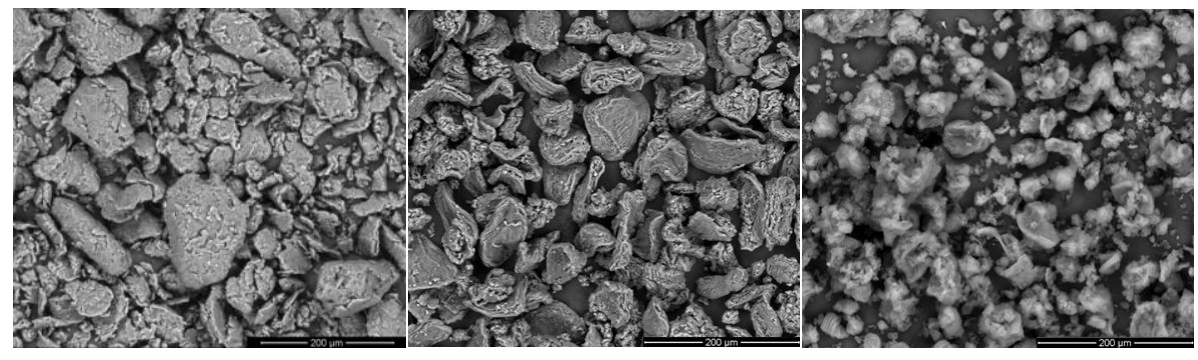

(a)

(b)

(c)

Figura 2: Micrografias das amostras (a) Q1, (b) Q2 e (c) Q3. Aumento de 500 x. 


\section{9 a 22 de outubro de 2014 \\ Florianópolis/SC}

Os processos de secagem utilizados nas amostras de quitosana interferem diretamente na área superficial e porosidade do material (tamanho e volume de poros). Com base nas informações extraídas das isotermas de adsorção/dessorção (não apresentadas) e nos dados da Tabela 1, as amostras de Q1 e Q2 possuem baixa porosidade e área superficial. Entretanto, para Q2, além da diminuição aparente do tamanho das partículas, quando comparada com Q1 (Figs. 3a e 3b), o aumento da área superficial se justifica também pelo incremento da rugosidade da superfície, causada pela rápida eliminação do solvente. Mesmo com volume de poros 8,5 vezes maior do que Q1, os poros da amostra Q2 possuem tamanhos reduzidos o que provavelmente está associado às torções sofridas pelas cadeias poliméricas durante a secagem, não somente na superfície, mas também no interior das partículas.

A precipitação de partículas de quitosana por SAS causou um grande aumento no valor da área superficial na amostra Q3 $\left(202,1 \mathrm{~m}^{2} \cdot \mathrm{g}^{-1}\right)$ devido à obtenção de partículas muito finas, com elevado volume de poros (32 vezes maior que Q2), o que tende a favorecer a exposição dos grupos amina. Aliado a estas características, o tamanho médio em torno de $15 \AA$ favorece o acesso de moléculas de tamanho cinético equivalente à faixa dos micro/mesoporos aos grupos amina. Tais características são capazes de potencializar a aplicação do material como adsorvente, o que será demonstrado a seguir através dos resultados de uso de Q1, Q2 e Q3 como adsorvente de amônia em efluentes aquícolas.

\subsection{Utilização de quitosanas com processo de secagem variado na adsorção de amônia em efluentes sintéticos}

Para a simulação de efluentes aquícolas foram preparadas soluções, identificadas como efluentes sintéticos, cujas concentrações de amônia (na forma de íons $\mathrm{NH}_{4}{ }^{+}$) abrangeram os teores mínimos nos quais espécies de ambiente aquático sofreriam alterações e danos fisiológicos, mas também extrapolaram consideravelmente os valores previstos para este tipo de ambiente. Sabe-se que algumas espécies como a truta arco-íris (Oncorhynchus mykiss) toleram limites máximos de amônia em torno de $0,3 \mathrm{mg} \mathrm{L}^{-1}$ enquanto outras como a tilápia do Nilo (Oreochromis niloticus) e catfish (Ictalurus puntactus) toleram níveis de 2,6 e $3,1 \mathrm{mg} \mathrm{L}^{-1}$, respectivamente.

A remoção de íons amônio $\left(\mathrm{NH}_{4}^{+}\right)$de efluentes é uma estratégia importante no controle do teor de amônia $\left(\mathrm{NH}_{3}\right)$ destes locais, pois embora a membrana de peixes não seja permeável a $\mathrm{NH}_{4}{ }^{+}$e sim a $\mathrm{NH}_{3}$, sabe-se que aumentos no $\mathrm{pH}$ do efluente provocam a conversão de íons amônio em amônia, resultando em toxicidade aos organismos.

Neste contexto, após obter amostras de quitosana cujas características físico-químicas oriundas do processamento de secagem indicaram potencialização de seu uso como adsorvente, testou-se o uso de tais amostras na remoção de íons amônio em efluentes sintéticos. No estudo inicial para uma concentração inicial fixa de íons amônio, variou-se a concentração do adsorvente a fim de determinar qual a menor concentração possível para uma alta eficiência de remoção (Figura 3).

Observa-se pelos resultados da Figura 3 (a) que quando o processo de secagem da quitosana é via $\mathrm{CO}_{2}$ supercrítico, a eficiência da remoção de amônia é praticamente $100 \%$ e cerca de $30 \%$ superior à remoção obtida quando o processo de secagem é feito em estufa. Nota-se ainda que, 


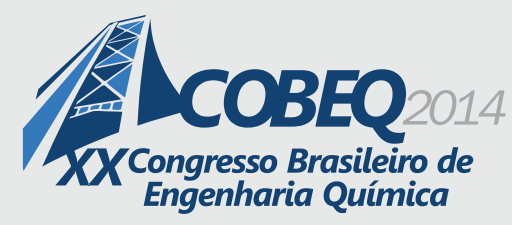

19 a 22 de outubro de 2014
Florianópolis/SC

embora a simples alteração do método de secagem em estufa (secagem em duas etapas) provoque aumento da área superficial (cerca de 16X) e do volume de poros (cerca de 9X) tais características não influenciam na performance da amostra em adsorção dos íons amônio. Observa-se ainda para a amostra Q3, a remoção de amônio em função da concentração de adsorvente praticamente não varia, o que favorece o aumento de escala, e que para as amostras Q1 e Q2 o aumento de 4 vezes na concentração de quitosana provoca pequeno aumento na eficiência de remoção (4\%).
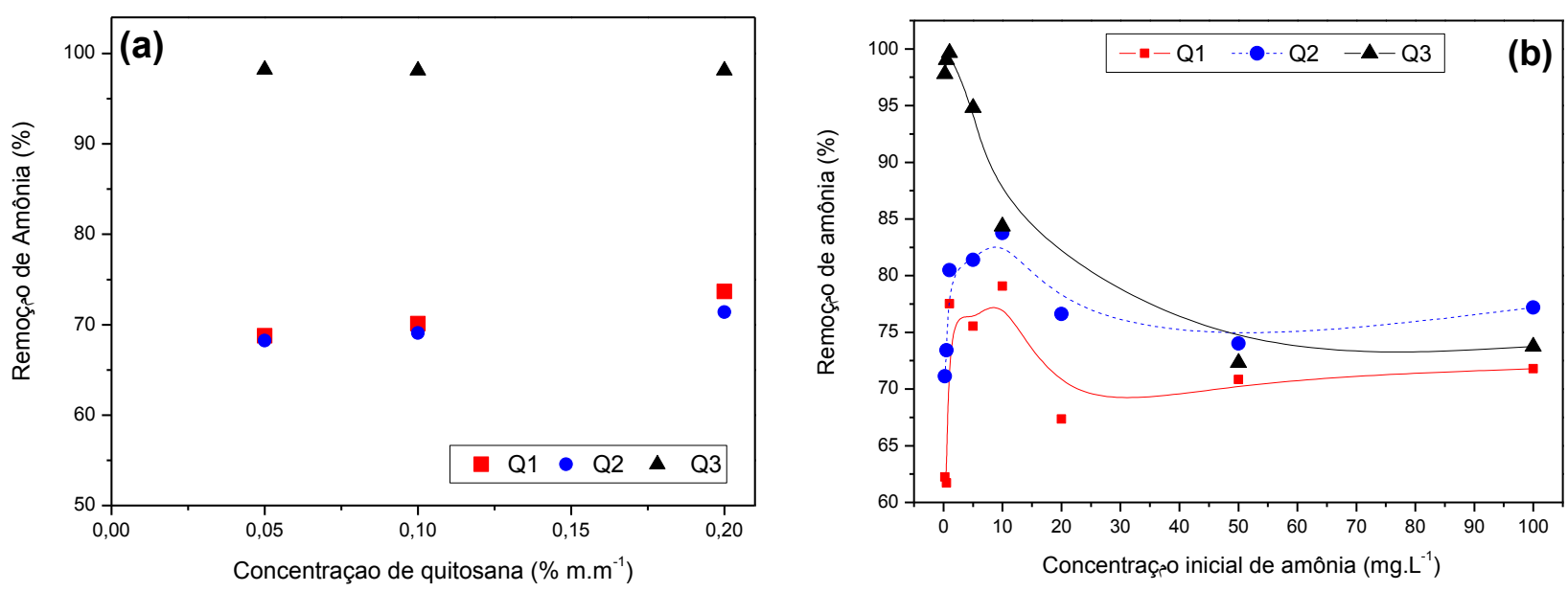

Figura 3: (a) Influência da concentração do adsorvente na remoção de amônia para $\mathrm{C}_{\mathrm{NH} 4+}=0,52$ mg. $L^{-1}, \mathrm{pH}=7,5$ e temperatura ambiente; (b) Influência da concentração inicial de $\mathrm{NH}_{4}{ }^{+}$sobre a eficiência do adsorvente

A partir das observações da Influência da concentração do adsorvente na remoção de $\mathrm{NH}_{4}{ }^{+}$ buscou-se avaliar o efeito da concentração inicial de íons amônio sobre a eficiência de remoção para a amostra que apresentou melhor resultado no ensaio anterior (Q3) e na menor concentração utilizada $\left(0,05 \% \mathrm{~m} \cdot \mathrm{m}^{-1}\right)$, que apresentou o mesmo efeito que para uma concentração quatro vezes maior. Os efluentes sintéticos preparados apresentaram concentrações de íons amônio que simulam o efluente real (de zero a cerca de $20 \mathrm{mg} . \mathrm{L}^{-1}$ ) bem como valores elevados (Figura $3 \mathrm{~b}$ ). Pela análise dos resultados é possível perceber que para as amostras Q1 e Q2 o aumento da concentração de íons amônio até cerca de $10 \mathrm{mg} . \mathrm{L}^{-1}$ favorece a adsorção que pode chegar a um máximo de $84 \%$ de eficiência (Q2). Para concentrações superiores a eficiência de remoção cai para valores entre $70 \%$ (Q1) e 77\% (Q2). Já para a amostra Q3 nota-se o aumento da eficiência com o aumento da concentração de íons até $1 \mathrm{mg} . \mathrm{L}^{-1}$ e para valores superiores a eficiência de remoção sofre queda até cerca de $74 \%$ para a maior concentração testada neste trabalho. Nota-se ainda que para concentrações de íons amônio acima de $50 \mathrm{mg} . \mathrm{L}^{-1}$ ocorre a saturação dos adsorventes utilizados.

\section{CONCLUSÕES}

A secagem por $\mathrm{CO}_{2}$ supercrítico provocou alterações marcantes nas características das partículas de quitosana: expressivo aumento do volume de poros e da área superficial, sem nenhum 
tipo de modificação estrutural. Tais características potencializaram a utilização da quitosana como adsorvente, o que foi demonstrado na eficiência de remoção de íons amônio em efluente sintético, sendo capaz de remover $98,2 \%$ dos íons utilizando a amostra seca por $\mathrm{CO}_{2}$ supercrítico, após 3 horas de agitação em pH 7,5 a temperatura ambiente, com apenas 0,05\% (m/m) de sólido adsorvente.

\section{AGRADECIMENTOS}

Os autores agradecem ao Prof. Dr. Lúcio Cardozo Filho (UEM/DEQ) pelo apoio na secagem das amostras por $\mathrm{CO}_{2}$ supercrítico.

\section{REFERÊNCIAS}

ARANA, L.V. Qualidade da água em aqüicultura - princípios e práticas. $3^{\text {a }}$ edição. Florianópolis: Editora UFSC, 2010.

GARCÍA-BERMEJO, A. B.; CARDELLE-COBAS, A.; RUIZ-MATUTE, A. I.; MONTAÑÉS, F.; OLANO, A.; CORZO, N. Effect of drying methods on the reactivity of chitosan towards Maillard reaction. Food Hydrocolloids, v. 29, p. 27-34, 2012.

KUBITZA, F. Qualidade da água na produção de peixes. $3^{\text {a }}$ ed. Jundiaí: CIP - USP, 2003.

LAZZARI, R. \& BALDISSEROTTO, B. Nitrogen and phosphorus waste in fish farming. Boletim do Instituto de Pesca, v.34, (4), p.591-600, 2008.

SANTOS, J. E.; SOARES, J. P.; DOCKAL, E. R.; CAMPANA-FILHO, S. Caracterização de quitosanas comerciais de diferentes origens. Polímeros: Ciência e Tecnologia, v. 13, p. 242-249, 2003.

TOLAIMATE, A.; DESBRIERESB, J.; RHAZIA, M.; ALAGUIC, A.. Contribution to the preparation of chitins and chitosans with controlled physico-chemical properties. Polymer, v. 44, p. 7939-7952,2003. 